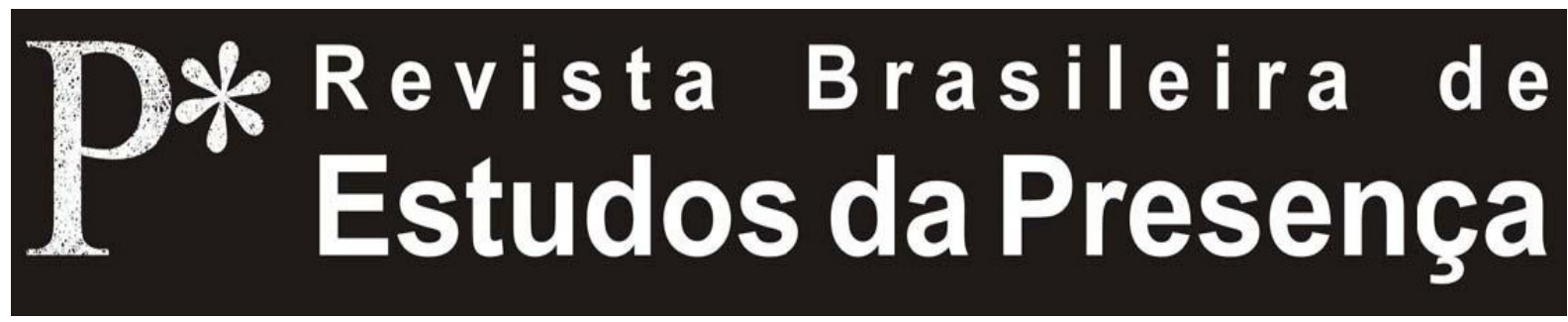

DOI - http://dx.doi.org/10.1590/2237-266029637

ISSN 2237-2660

\title{
La Relectura de los Cuerpos en el Teatro Frente a las Mediatizaciones de lo Cotidiano
}

\author{
Carlos Fos \\ Asociación Argentina de Crítica e Investigación Teatral - Buenos Aires, Argentina
}

\begin{abstract}
RESUMEN - La Relectura de los Cuerpos en el Teatro Frente a las Mediatizaciones de lo Cotidiano - El objetivo del presente trabajo es analizar las dificultades para sostener convivios en las sociedades contemporáneas. Partiendo de los obstáculos impuestos para las relaciones que impliquen el juego corporal y los encuentros festivos de ecos sacros, llegamos a definir colectivos presos a las mediatizaciones que padecen. Para avanzar en esta pesquisa utilizamos herramientas aportadas por la antropología y la etnohistoria. Incluimos también elementos recogidos en trabajo de campo, que forman parte de un proyecto de recuperación de elementos rituales fragmentados en la memoria de la comunidad. Con estos instrumentos podemos dar los primeros pasos para apartarnos de definiciones esencialistas y promover la relectura de los cuerpos.

Palabras-claves: Cuerpo. Fiesta. Aculturación. Identidad. Teatro Ritual.
\end{abstract}

ABSTRACT - The Reinterpretation of the Body in Theater in Face of Everyday Mediations - The present work aims at analysing the difficulties in keeping relationships in contemporary societies. Starting from obstacles imposed on relationships involving physical games and festive meetings of a religious character, we defined groups and the mediations they are subjected to. In this research we used tools provided by anthropology and ethnohistory. We also included information gathered in field work, which is part of a project to recover fragmented ritual elements in the memory of communities. With these instruments we were able to take the first steps away from reductionist definitions and promote the reinterpretation of the body. Keywords: Body. Party. Acculturation. Identity. Ritual Theater.

RÉSUMÉ - La Relecture des Corps dans le Théâtre Face aux Médiatisations du Quotidien - L'objectif du présent travail est d'analyser les difficultés à soutenir les cohabitations dans les sociétés contemporaines. Partant des obstacles imposés par les relations qui impliquent le jeu corporel et les rencontres festives d'echos sacrés, nous sommes parvenus à définir des collectifs pris aux médiatisations qui souffrent. Pour développer cette recherche, des outils de l'anthropologie et de l'ethno-histoire ont été empruntés. Ont été ajoutés également des éléments recueillis dans le travail de terrain faisant partie d'un projet de récupération des éléments rituels fragmentés dans la mémoire de la communauté. Avec ces instruments nous sommes en mesure de faire les premiers pas afin de nous écarter de définitions esencialistas et de promouvoir la relecture des corps.

Mots-clés: Corps. Fête. Acculturation. Identité. Théâtre Rituel. 


\section{Las Trampas de una Sociedad sin Cuerpos}

¿Es posible entender micro o macro-sociedades sostenidas en la falta del encuentro personal? El tejido social se enhebra en la reunión de los cuerpos, en el intercambio fructífero del uno con el otro complementario. Un trueque que no puede concebirse a distancia, o escapando al compromiso presencial. Cuando los sectores hegemónicos avanzan sobre los pueblos, agreden su capacidad de pensarse críticamente desde múltiples posiciones, haciendo gala de recursos cada vez más numerosos y sofisticados. La noción de las relaciones mediatizadas (por las herramientas tecnológicas actuales), como sustitutos de las que se constituyen desde los rituales cuasi-sacros de la corporeidad en juego y ofrenda, es funcional a los esquemas de dominación. Sin embargo, el hombre mantiene espacios de resistencia a este mandato por generar colectivos sin fiesta, reformulándolas como lugares de articulación y convivio que contribuyen a reforzar las identidades locales, desde posiciones no esencialistas. Es necesario detenernos un instante, para reflexionar acerca de cómo responden estos espacios de encuentro en una sociedad multiforme y globalizada. Durante décadas, la aproximación científica a los fenómenos culturales vinculados a la fiesta ha pretendido describirla como un todo inmodificable, o en el mejor de los casos, como una síntesis o hibridación de elementos mágicos, lúdicos, teatrales, religiosos. Este posicionamiento conlleva una carga de fetichismo objetal muy grande, ya que no analiza los cambios verificados en las concreciones de los colectivos, limitándose a un epidérmico y aun banal resultado. Asimismo, este abordaje tiende a la pérdida del concepto de proceso cultural, dejando a sus productos aislados y sometidos a interpretaciones capciosas y conservadoras. Las fiestas que podemos registrar hoy, son el resultado de múltiples acciones de aculturación, intercambio de procedimientos, resemantizaciones, que no pueden ser tratadas como monumentos de simple interpretación, en búsqueda de responder a perimidos discursos sobre patrimonio e identidad.

Claro que, todavía presas de mutaciones y procesos de degradación, que las tornan por momentos irreconocibles, las fiestas encuentran resquicios para filtrarse a través de 
transacciones que suelen arrebatarle parte de su carga sacra. Esta laicización, empero, es incapaz de quebrar temas míticos, espina dorsal de la preservación de los pueblos. Con inversión de sentido, haciendo concesiones a la reglas del mercado, los ritos permanecen, aunque sus orígenes sean indescifrables para muchos de los que los practican. En las reuniones y las pseudo fiestas degradas actuales, controladas por la lógica del entretenimiento banal y la satisfacción no alcanzada, los trazos de esas repeticiones de ritos de apareamiento, muerte, resurrección son detectables. Y detrás de estas mecánicas acciones, no registradas críticamente por el ocasional celebrante, hay evocaciones míticas. Si sumamos a las fiestas populares como el receptáculo que mantiene el legado de cuestionar los poderes imperantes y poner en relatividad las verdades oficiales, nos hallamos con fuertes diques para el avasallamiento de las diferencias como particularidades creadoras de las comunidades. Con una impronta subversiva, corroe las pautas del mundo mediado, transitando un camino opuesto al que éste promueve. A la presencia de cuerpos dóciles, le responde con libertad absoluta y conciencia de sí; a la despersonalización, le contrapone la reafirmación de individuo en su pertenencia al colectivo; y al tiempo de las leyes de la producción capitalista le contraoferta un tiempo mágico, primitivo, sanador. En este tiempo de raíces sagradas, los llamados de la horda se hacen patentes y, con los límites que los mismos participantes le ponen, la posibilidad de asestar un golpe momentáneo a las regulaciones y a las castas jerárquicas que les dieron vida está al alcance de la mano. Un devenir temporal distinto, que privilegia la horizontalidad, faculta la intervención de todos por igual y perpetra una revuelta contra el sistema de apreciación de las disposiciones que nos encorsetan.

Fiesta popular profana o festividad religiosa que encierra elementos de las fiestas ancestrales, son hoy buscadas por algunos teatristas como fuente de recursos para sus creaciones. Cuando la comunicación real entre los miembros de los colectivos está seriamente afectada o se reduce a codificaciones acríticas, los ritos surgen como canales válidos para restablecer los contactos perdidos o sesgados. Esa comunicación con lo sobrenatural y con el marco cultural circundante le otorga al 
rito un valor trascendental. En estado festivo no hay personas ajenas a esta instancia de conexión plena; actores y espectadores son depositarios de los saberes verbales y corporales (codificados en danzas, cantos, poemas a las divinidades, etc.) y cada uno lo ejercerá de acuerdo a sus funciones durante las celebraciones. Un entramado simbólico que prolongará los lazos entre los hombres más allá de la duración de la propia fiesta; esa comunicación se manifiesta en él durante y en lo post, con interesantes relaciones entre ambos momentos. La empiria y su proyección fuera del rito son visitadas por la antropología desde múltiples perspectivas. Es tiempo de explicitar los puentes que se han tendido en los últimos años entre estas instancias festivas y las realizaciones de un teatro que se autoproclama de extracción ritual. Lo haremos como un bosquejo inicial, como un acercamiento a una concepción dramática y escénica que se reivindica en el lugar de la restauración de las memorias, en el lugar del pleno ejercicio de la corporeidad.

Cuando los proyectos impuestos por los sectores dominantes no pueden generar resignación en el imaginario colectivo, suelen resultar procesos de resistencia cultural. Estas acciones, algunas veces conscientes y otras tantas no, son una forma de preservación de la existencia misma. A pesar de los intentos de alcanzar un teatro sumiso, continúan emergiendo discursos escénicos genuinos, atravesando las grietas, escurriéndose por los suburbios de lo establecido. Y lo hacen como respuesta a las múltiples caras del acto creador, posicionándose contra los designios de la tabla rasa globalizadora. De acuerdo a esta perspectiva, el teatro no es un lenguaje en crisis terminal. Por el contrario, se convierte en una expresión que rechaza el discurso de los poderosos y aun el camaleónico contracultural, preferido por el indefinido progresismo. Como en un tremendo salto hacia delante, abandona la seguridad de siglos y busca su original definición de lenguaje ancestral, un lenguaje escondido en la maraña de productos culturales nacidos de la hibridación, intercambio y aculturación. El hombre es vuelto a ser tratado desde su dimensión más inmediata, su medida esencial: su cuerpo. Y desde ese territorio personal se avanza hacia las construcciones de los encuentros primarios, ya libres 
de la violencia recíproca, en el ámbito de lo tribal. Se abandonan las posiciones macro, para abordar lo territorializado. Pero no se trata de una fragmentación más con el objetivo de sumar confusión ni tampoco de sostener los argumentos de la historia oficial. Por el contrario, es un proyecto que retoma voces sometidas, voces de una riqueza multiplicadora. Y en esta posición refleja más preguntas que respuestas cerradas e irreductibles. Cuestionamientos que bucean sobre los mecanismos instrumentados para borrar los aspectos positivos de los rituales, para desenmascarar las prácticas que erosionan las bases míticas de una sociedad y la dejan sin defensa ante la agresión externa.

Pero no es tiempo de teorizar solamente sobre los males de la pérdida de estos convivios festivos. Se requiere ponerle un dique a este proceso de disgregación. Para ello, la comunidad ha buscado a través del arte una herramienta adecuada. $Y$ el teatro dio respuestas a través de la fiesta, entendida como encuentro, como celebración de la memoria. En este último caso, la memoria no busca la cosificación del pasado, aislándolo de las circunstancias históricas que lo animaron, descontextualizándolo. En sentido inverso, se ocupa de dar explicaciones, información retaceada o camuflada durante años, que ponga en un punto de encuentro a los materiales del promovido patrimonio cultural (publicitado en sus virtudes como atractivo turístico) con las particularidades de los colectivos que le dieron vida. También promueve el repensar la relevancia de esos materiales a la luz de la paleta de las identidades que conforman a estas comunidades, dejando en claro la pérdida de sentido de algunos de ellos y la revalorización de otros poco señalados.

Se trata de un gran salto de abstracción teórica, imprescindible para ponderar a la identidad como un proceso de identificaciones históricamente apropiadas, que le confieren sentido a un grupo social. Este proceso es capaz de darle estructura significativa a este mismo colectivo para que pueda asumirse como unidad en la pluralidad. Desde un espacio que trabaja con instrumentos relevantes para la reconstitución de la memoria, es posible caer en la tentación de apegarnos afectivamente a las piezas que vamos recuperando en el largo camino 
de la reconstrucción. Esta tensión entre criterios antagónicos demanda un esfuerzo considerable, ya que estamos tironeados por la tradición de procedimientos de inventario. Cada gestualidad, mirada o expresión de los cuerpos restañados en su significado no deben ser sacrificados, pues se le restarían las dimensiones espacio-temporales en las que nacieron. De lo contrario, la violencia recíproca que evocan o la perentoriedad del encuentro que exigen, quedan sustituidas por simples listas descriptivas de rasgos deshilachados. Si practicamos ese reduccionismo seremos capaces de conmocionar a la comunidad desde la emotividad melodramática, pero cerramos la puerta a la fuerza renovadora del ritual revisitado. La pesquisa necesaria es la que vuelve sobre el material y lo cuestiona en cuanto a su validez en el presente. Lo festivo ha sido domesticado, estratificado, neutralizado en su capacidad subversiva para cuestionar la noción misma de cultura. Y se eligieron tácticas distintas: la degradación progresiva, la codificación en elementos dispersos sin lógica interna, sean estas técnicas teatrales de tinte ritual o prácticas lúdicas populares. No es posible que las celebraciones, las de extracción sagrada como las laicas, carezcan de ese poder revulsivo, de esta potencia que nace del jugar las presencias en un aquí y ahora marcado por el devenir mágico. Y la medida de este adoctrinamiento de los pueblos para evitar esas reuniones significativas está dada por el grado de sujeción a axiomas como el de que todo tiempo pasado fue mejor. Una frase cargada de ideología negativa, repetida para ingresar en el pensamiento colectivo y transmitirse. Esta expresión condena a los que, desesperados por la falta de circulación de deseo creador, se aferran a ideas y procedimientos de improbables territorios dorados pretéritos sin convicción. Esas ideas les son ajenas, carecen de valor representativo en el presente de sus vidas. Un teatro desde la paleta de memorias comunitarias no puede construirse sobre pilares inestables que auspicien la disección positivista de la cultura en rasgos autónomos. No puede poblarse una malla social deteriorada partiendo de hechos o facetas comprensibles por sí mismos; los productos culturales nacidos sin el sustento de una cadena histórica que los anime y resguarde con sus ecos míticos serán un pobre resultado apto para la transacción 
de una sociedad mercantilizada. Realimentamos la mentada imposibilidad del encuentro, el reemplazo del mismo por opciones que estimulan la individualidad extrema y la soledad travestida en contactos electrónicos.

Como vemos, se produce un choque de fuerzas desiguales, de vectores culturales asimétricos en cuanto a los sectores de poder que los sostienen y propagan. En un extremo de esta soga en curiosa cinchada se hallan formas estéticas que proclaman un mundo del eterno presente, sin pasado (tan sólo crónicas aisladas y anecdóticas) real y sin futuro posible; un abismo de carencias utópicas recortado por la fugacidad de la experiencia y la fragmentación del fundamento. En oposición, cosmovisiones autóctonas, con un imaginario social modernizante, defensores de estéticas territorializadas, que escapan de la banalidad y se recuestan sobre los cimientos de la memoria, registrada por el colectivo en actividades colectivas presenciales.

\section{En el Camino del Registro Festivo}

No importa el origen de las cosmovisiones, ya que esta pretensión de pureza, como vimos, es imposible. Lo que cuenta es la autenticidad de las mismas; es decir, que sean la síntesis de un proceso de revisión y observación crítica de su estado. Que al buscar, hurgando en la memoria común, los que animen estas cosmovisiones comprendan que las mismas son hijas del trueque, de la colonización, del intercambio por contacto con otras cosmovisiones. De esta manera, las experiencias culturales contemporáneas aparecerán como espacios para el registro de las diferentes degradaciones inducidas por el poder interno y externo. El primer paso es internalizar la realidad pluricultural de los pueblos y detectar los elementos exógenos, impuestos como realidades de convivencia cotidiana. Otro punto para ejercitar el pensamiento crítico que nos apartará de los mecanismos de las culturas centrales para desarraigar o integrar a las periféricas y de las ópticas puristas, ambas erróneas.

Expresados estos considerandos, imprescindibles para aproximarse a cualquier objeto de estudio, volvemos a la fiesta 
como centro de reunión efectiva, sin mediaciones tecnológicas. Las fiestas sacras, cuyos rituales se intentan traer al presente mediante herramientas aportadas por la etnohistoria y la historia oral de registro, las fiestas populares y el teatro celebrante, entendido como el diálogo entre elementos de las primeras y técnicas y poéticas escénicas actuales, se constituyen en defensoras de la supervivencia de los pueblos que las animan.

A las experiencias, que con cierta continuidad se desarrollan en diversos lugares de Centro y Norteamérica, debemos agregar el comienzo de un recorrido similar en nuestro país. Partimos de fiestas en su estado actual de aculturación e iniciamos un viaje en el recuerdo, científicamente colectado, de los miembros de la comunidad para visibilizar cantos, movimientos, fragmentos de ritos parcialmente distorsionados. Un viaje esquivo, en muchos casos, aunque apasionante aun en los senderos truncos. Esta investigación, generalmente de considerable e imponderable duración, culmina con la revaloración de elementos invisibilizados, que se ponen a consideración del colectivo celebrante para que los evalúen como enriquecedores o los descarten por ser incompatibles con su realidad. De cualquier manera, los movimientos rituales, el juego de cuerpos, el compromiso vivencial, son compartidos con aquellos que puedan tener interés, proviniendo los mismos desde distintas disciplinas de las ciencias y de las artes. Hay teatristas que se aproximan con respeto en búsqueda de trueque con sus saberes, cerrando un círculo en el sacrificio oficiado en el escenario. El abordaje del material se hace desde los lineamientos que animan a cada grupo en particular y los resultados son múltiples. Las tentaciones de caer en superficiales miradas en respuesta a demandas del mercado se hallan presentes. De la reacción de los elencos dependerá la calidad del producto final.

En Argentina y, a través de diversos acuerdos con sectores oficiales, universitarios e independientes, hemos diseñado estrategias y empezado el trabajo en campo con la comunidad de origen mapuche desplazada en la zona de Los Toldos, en la Provincia de Buenos Aires. La aspiración del equipo multidisciplinario en formación es sentar las bases de un trabajo similar al desarrollado en México y Centroamérica, teniendo 
en cuenta las diferencias propias de tratar con cosmovisiones, realidades sociales, económicas, geográficas y políticas distintas. El objetivo más ambicioso es que nuestras acciones promuevan la reconstrucción de la memoria de un colectivo silenciado, agredido sistemáticamente con intentos de asimilación y que responde a procesos históricos no funcionales a las posiciones científicas hegemónicas. Con recursos ya probados, volvemos a contar con las fuentes orales obtenidas en el trabajo de campo como centro de nuestra pesquisa. Allí donde no se dispone de documentos escritos, los testimonios de los protagonistas registrados con rigor científico se transforman en fuentes de valor apreciable. Por supuesto se cruzarán los testimonios con la información proveniente de archivos y textos de viajeros, corroborando sistemáticamente la verosimilitud de lo conseguido. En una comunidad con una rica tradición narrativa esta perspectiva nos abre muchas instancias para avanzar, con la prudencia requerida. La oralidad es un río caudaloso en el que podemos caer si olvidamos el distanciamiento necesario de el discurso registrado. La mirada entrenada nos pide olvidar empatías para interpelar las voces de los interlocutores. Es imprescindible detenernos en su lenguaje corporal, en los silencios, con los que completaremos el testimonio. La repregunta, la confrontación con las propias contradicciones nos permitirán ir ordenando y darle sentido al material en bruto. Claro que esa estructura que vayamos reconstruyendo, a través de las relaciones dialógicas, no puede ser concebida como rígida y menos como totalizadora. Cada nuevo elemento será pasado por el tamiz de la confrontación con otros discursos, incluyendo el del mismo entrevistado. En una pesquisa que dura meses, los miembros de un grupo darán versiones diferentes y, en la medida que la interacción genere confianza mutua se obtendrán piezas orales de mayor riqueza. Sostener la posición de intercambio es fundamental, ya que cualquier actitud soberbia, que sugiera expresiones civilizadoras, promoverá la resistencia de los colectivos, entendida esta resistencia como genuina defensa. Insistimos en que no se trata de observaciones anecdóticas, con un mapa de ruta errático. Estamos hablando de primeros pasos seguros, fundados en apreciaciones y tópicos que respondan a la 
reflexión previa del antropólogo, que disparó su búsqueda. Es imprescindible caminar por una delicada y equilibrada línea para no dejarse llevar por la emergencia de materiales no tenidos en cuenta al comienzo o rechazarlos en el supuesto beneficio de una investigación coherente pero carente de flexibilidad. De no cruzar esta delgada línea hacia ninguno de los extremos pontificados, depende parte del éxito del trabajo. No trabajamos desde la inocencia del diletante, pero tampoco nos encerramos en parámetros intelectuales inmutables. Si lo hiciéramos esa incógnita de la otredad no se plantearía como tal, ya que los presupuestos bastarían para deformar cualquier aporte conseguido en el trueque de información. Sumergirse en el mundo del distinto, siempre ha resultado complejo para una ciencia que siguió los principios del positivismo durante décadas. Partimos de nuestra experiencia de sociedad, un entramado en el que el eros electrónico pretende convertirse en canal del deseo.

El punto de vista de la comunidad transitada, con la internalización de discursos ajenos, se muestra desafiante, con lugares centrales para la experiencia compartida. Experiencia sacra, lúdica, sanadora, manifestada en los rituales festivos. El reconocimiento mutuo se dará en espiral, con avances y retrocesos, reflejos de la tensión entre mundos que no están aislados (en muchos casos las fronteras se pierden en su porosidad, siempre desde la dominancia del que detenta poder), pero que son productos de síntesis culturales distintas. Ese viaje inter-subjetivo hacia la fiesta, sacro-convivio, modificará a ambas partes, no las dejará indemnes. En esta fase germinal del proyecto en Los Toldos, se incorporan leyendas ya transitadas por recopiladores o artistas extraños a la comunidad. En el mismo sentido se han reconocido danzas y cantos, contextualizados en la Fiesta del Encuentro. En esta mirada voyeurística sobre el ritual y las fiestas que los contienen, sigue latente la pregunta inicial. Las sociedades han sido fundadas en los encuentros personales; ellos son los que fomentan las relaciones, las alimentan. En las comidas sagradas, en las fiestas paganas, en el teatro celebrante nos topamos con los cuerpos erotizados, ansiosos, mezclados, como señales de vida, de circulación de la violencia benéfica. 
Carlos Fos es antropólogo e historiador teatral. Director de proyectos de investigación sobre teatro obrero y de fuentes. Presidente de la Asociación Argentina de Crítica e Investigación Teatral. Director del Centro de Documentación de Teatro y Danza del Complejo Teatral de Buenos Aires.

E-mail: cfos@complejoteatral.gob.ar

Recebido em 21 de maio de 2012

Aprovado em 11 de agosto de 2012 